\title{
Does Partisanship Affect Compliance with Government Recommendations?
}

\section{Masha Krupenkin ${ }^{1}$ (D)}

Published online: 5 May 2020

(c) Springer Science+Business Media, LLC, part of Springer Nature 2020

\begin{abstract}
This article studies the role of partisanship in American's willingness to follow government recommendations. I combine survey and behavioral data to examine partisans' vaccination rates during the Bush and Obama administrations. I find that presidential co-partisans are more likely to believe that vaccines are safe and more likely to vaccinate themselves and their children than presidential out-partisans. Depending on the vaccine, presidential co-partisans are 4-10 percentage points more likely to vaccinate than presidential out-partisans. Using causal mediation analysis, I find that this effect is the result of partisans' differing levels of trust in government. This finding sheds light on the far-reaching role of partisanship in Americans' interactions with the federal government.
\end{abstract}

Keywords Partisanship · Vaccination · Vaccines · Government regulations · Public health · Antivaccine

Political partisanship is a major force in Americans' daily lives. As polarization grows (Iyengar et al. 2012), partisans are more likely to use their partisanship as a heuristic when choosing not only who to vote for, but who to work for, socialize with, and date. While the effect of partisan polarization on interpersonal relationships is well known, its effect on Americans' interactions with their government is not as well understood. Direct partisan cues may limit participation in the most polarizing programs (Lerman et al. 2017), but the US government quietly

The author thanks Mike Tomz, Shanto Iyengar, Tali Mendelberg, Paul Frymer, David Broockman, and Keith Wailoo for their helpful advice and critiques. Replication data for this paper can be found at: https://masha-krupenkin.com/vaccines-replication

Electronic supplementary material The online version of this article (https://doi.org/10.1007/s1110 9-020-09613-6) contains supplementary material, which is available to authorized users.

Masha Krupenkin

masha.krupenkin@bc.edu

1 Boston College, 140 Beacon Street, Chestnut Hill, MA 02467, USA 
issues thousands of regulations and recommendations every year. In this article, I study the role of partisanship in Americans' acceptance of government vaccination recommendations.

Are partisans less likely to comply with government recommendations after their party loses the presidency? To answer this question, I combine survey and behavioral data to examine the effect of presidential co-partisanship on partisans' willingness to vaccinate.

Vaccination provides an especially fertile testing ground for my theory for three reasons. First, both Republican and Democratic administrations have recommended vaccination as a public health measure. This provides natural variation in control of government, while keeping the government recommendation constant. Second, there is significant survey and behavioral data on vaccine compliance. This allows me to test the effect of partisanship both on peoples' beliefs about vaccination, and their actual vaccination behavior.

Finally, vaccination provides a "hard test" of the hypothesis, since the consequences of non-compliance can adversely impact individuals' health. If partisanship affects receptivity to vaccination, this finding has important implications for the acceptance of other government interventions that do not carry such high costs for non-compliance. Most studies that show a partisan effect on non-political behaviors focus on interpersonal behaviors, such as perceptions of attractiveness (Nicholson et al. 2016), mate choice (Iyengar et al. 2017; Huber and Malhotra 2012), and employment (Gift and Gift 2015). Vaccination decisions that impact the health of the child represent a more stringent test of partisan spillover into the domain of nonpolitical behaviors.

I find that partisans are indeed more likely to report intent to vaccinate when their party holds the presidency. Furthermore, I find that actual vaccination rates among partisans change after a change in the party of the presidency. These differences are not the result of partisan differences in beliefs about the severity of the disease, but rather, are attributable to their differences in perceptions of vaccine safety. I also find that differences in government trust significantly mediate the effect of partisanship on perceptions of vaccine safety.

In the next section, I discuss the theoretical debates that motivate this research. In the third section, I present the data and empirical strategies used to measure the partisan vaccination gap. The fourth section examines the survey evidence for partisan gaps in perceptions of vaccine safety in three cases, one under a Republican president and two under a Democratic one. The fifth section uses causal mediation analysis to test the relationship between trust in government, partisanship, and vaccination rates. The sixth section analyzes the effect of partisanship on actual vaccination rates. Finally, I conclude by discussing the implications of these findings.

\section{Theory}

I argue that polarization influences partisans' willingness to follow government recommendations by reducing their trust in government when the opposing party holds the presidency. Distrust of members of the out-party has dramatically risen 
over the course of the past two decades(Iyengar et al. 2012; Mason 2016). Not only do partisans hold very negative beliefs about members of the opposing party, they are likely to discriminate against them (Iyengar and Westwood 2015). Almost half of partisans believe that policies espoused by members of the outparty are "so misguided that they threaten the nation's well being" (Pew Research Center 2016). Given this deep dislike of the opposing party, it is unsurprising that partisans would be mistrustful of the federal government when the opposing party is at its' helm.

Indeed, evidence suggests that in highly polarized political environments, partisans are unlikely to trust the out-party (Vegetti 2014). Presidential co-partisans are significantly more likely to say that they trust government than presidential out-partisans (Schaffner and Clark 2004; Pew Research Center 2010). In a weekly analysis of government trust in 2000-2001, Schaffner and Clark (2004) find that Democrats were more trusting of the federal government than Republicans until the Supreme Court decision in Bush v Gore confirmed Bush's victory in the presidential election. Keele (2005) finds that changes in party control of the presidency have a much greater impact on trust in government among partisans than do changes in control of Congress.

Presidential visibility is the most compelling reason why partisans are more likely to focus on the party of the president, rather than control of Congress, when deciding whether or not to trust the government. The president is far more visible than members of either house of Congress. Only $36 \%$ of Americans can correctly name which parties control Congress (Sullivan 2014), compared to the $85 \%$ who can identify the party of the president (Pew Research Center 2012). Presidents successfully exploit their superior visibility, appealing to the public to further their own policy ends at the expense of Congress (Canes-Wrone 2010).

People will be more likely to follow government regulations when their party is in power because they are more likely to cooperate with entities that they trust. Citizens who have trust in the government will be less likely to see government regulation as arbitrary, unfair, or harmful, and will thus be more likely to comply with government regulation. The empirical evidence supports this argument. High levels of trust yield more co-operation with government programs (Owen and Videras 2008; Braithwaite and Makkai 1994). Republicans, who are more likely to trust the free market than are Democrats, were more likely to sign up for Affordable Care Act's health care exchanges when they were framed as a "free market" alternative (Lerman et al. 2017).

Trust in governmental authority is a well-known predictor of compliance with government recommendations and interventions in a variety of arenas, including vaccination. The first opponents of vaccination, which arose in the mid 19th century in opposition to British smallpox vaccination laws (Porter and Porter 1988) cited their distrust of government and the medical profession as reasons for doubting the vaccine's safety. Distrust of the government was an especially salient reason for working class Britons to resist smallpox vaccination (Durbach 2004), illustrating how prior societal divisions which lead to differences in government trust can also lead to differential acceptance of government intervention. While the divisions between Democrats and Republicans today may not be as large as those between 
lower and upper class Britons in the 19th century, they still can have a strong influence on government trust.

Partisan media cuing effects pose a possible alternative explanation for the partisan vaccination gap. Baum (2011) argues that Republican were less likely to vaccinate for H1N1 because of Fox News media coverage that disparaged the H1N1 vaccine. If partisan news organizations report on vaccines differently depending on the partisanship of the president, selective exposure to partisan news could serve as a driver of the partisan vaccination gap. However, there is significant debate on the extent of selective exposure. Some scholars find evidence that partisan selective exposure is fairly rare (Prior 2013) and few Americans only consume news sources that align with their partisan affiliation, while other find that partisan selective exposure is more common (Peterson et al. 2019).

In summary, I predict that presidential co-partisans will be significantly more likely to accept government recommendations than presidential out-partisans. Furthermore, I argue that partisan differences in acceptance of government recommendations are primarily rooted in differences in government trust. Presidential out-partisans are less likely to believe that government recommendations are safe or effective than partisans whose party is in power.

\section{Empirical Approach}

In order to test my theory about the relationship between government trust, partisanship, and vaccination, I rely on three distinct sets of analyses. The first set uses surveys to look at partisans' stated beliefs about vaccine safety and willingness to get vaccinated over the course of the George W. Bush and Barack Obama administrations. The second set uses causal mediation to better understand the relationship between government trust and partisan perceptions of vaccine safety. The third and final set of analyses uses vaccination data from California to measure the effect of the change in the party of the president on actual vaccination behavior.

\section{Survey Measures of Individual-Level Beliefs About Vaccination}

I use survey data to measure two quantities of interest-perceptions of vaccine safety and reported willingness to receive the vaccine. Surveys are a reliable tool for measuring both vaccine risk perception and vaccination behavior. Survey responses to questions about vaccine risk perception have shown to accurately predict actually vaccination behavior (Brewer et al. 2007). Vaccination surveys, such as the National Immunization Survey (NIS), are used to craft public health policy in the US. In addition to directly surveying parents about their children's vaccination status, the NIS uses health provider vaccination records to validate parental responses. This methodology shows that parental survey responses and vaccination records have 
relatively high agreement. ${ }^{1}$ Other studies also show that adult survey respondents tend to accurately report their own vaccination status (For examples, see Mac Donald et al. (1999) and Zell et al. (2000)).

While some scholars have found evidence of partisan expressive reporting about economic questions on surveys (Bullock et al. 2015; Prior et al. 2015), it is unlikely that partisans engage in expressive reporting about their vaccination beliefs. When partisans expressively report on surveys, they answer questions strategically in order to make their own party look good, rather than answering them sincerely. Economic performance is a traditional marker of a president's performance, and as a result partisans are likely to answer those questions strategically. Vaccine safety is not traditionally used to measure a president's performance in the same way as the economy, so partisan expressive reporting about vaccine safety is therefore unlikely.

My main independent variable of interest is party identification, split into three categories: Republican, Democrat, and independent. The independent category was limited to pure independents - leaners were categorized with their respective party. ${ }^{2}$ In 2002, Democrats and Democratic leaners made up $40 \%$ of the population, while Republicans and Republican leaners were $44 \%$ of the population. Pure independents made up only 7\% of the population (The American National Election Studies 2017).

I use an ordered logistic model with controls for age, gender, race, income and education to measure the effect of partisanship on perceptions of vaccine safety, and a binomial logit model with the same control variables to measure partisans' willingness to vaccinate.

To estimate the actual effect size of partisanship on perceptions of vaccine safety and willingness to vaccinate. ${ }^{3}$ I calculated two separate sets of predicted probabilities for the entire population using a logistic model. These two sets of predicted probabilities represented each respondent's probability of vaccinating in the counter-factual world in which all respondents were Democrats, and the counter-factual world in which all respondents were Republicans. Finally, I subtracted one set of predicted probabilities from the other to get the effect size of partisanship.

I look at three cases of partisan vaccination gaps. One of these is the smallpox vaccine in 2003, during the Bush administration. The other two are the swine flu (H1N1) and measles vaccines in 2009 and 2015, both during the Obama administration. This allows me to test whether Democrats and Republicans switch their perceptions of vaccine safety depending on which party is in power. Here, I will briefly describe the surveys and questions used to measure perceptions of vaccine safety and willingness to vaccinate for each of the three cases.

\footnotetext{
${ }^{1}$ https://www.cdc.gov/nchs/data/series/sr_01/sr01_061.pdf.

${ }^{2}$ Unfortunately, none of the surveys available asked about strength of partisanship, so a test of strong partisan vs weak partisan was not possible. Additionally, when tested separately, leaners behaved very similarly to partisans of the party they lean towards. This is not too surprising, as leaners often mirror weak partisans in their political behavior.

${ }^{3}$ Partisanship is often correlated with factors such as gender and race that significantly influence risk perception. For example, white men (Finucane et al. 2000) are more likely to underestimate risk - they are also more likely to be Republicans.
} 
Smallpox: Perceptions of vaccine safety were measured using several questions from the nationally representative April 2003 Harvard School of Public Health SARS survey $(\mathrm{n}=1003)$, which asked respondents about the probability of experiencing a range of side effects such as serious illness or death from the smallpox vaccine. This variable was reported on a four-point scale ranging from "not likely at all" to "very likely", and $26 \%$ of all respondents claimed that death was a very or somewhat likely side effect.

Willingness to vaccinate was measured with a question from the nationally representative January 2003 Gallup/CNN/USA Today poll $(n=1000)$, which asked respondents whether they would get the smallpox vaccine if it were to become available. The responses were fairly equally split, with $53 \%$ of all respondents saying they would get the vaccine, and $44 \%$ saying they would not.

H1N1: Perceptions of vaccine safety were measured using several questions from the nationally representative October 2009 ABC/Washington Post survey (n $=1004$ ), which asked respondents about their confidence in the safety of the H1N1 vaccine. This variable was reported on a four-point scale from "Not at all confident" to "Very confident", with $30 \%$ of all respondents "Not at all confident" or "Not very confident" in the safety of the vaccine.

Willingness to vaccinate was measured with a question from the same $\mathrm{ABC} /$ Washington Post survey, which asked respondents whether they were willing to get vaccinated for $\mathrm{H} 1 \mathrm{~N} 1$. In this case, $62 \%$ of respondents said that they were unlikely to get the H1N1 vaccine.

Measles: To collect data on attitudes toward the measles vaccination, I ran a nationally diverse survey through Survey Sampling International $(n=4570)$ that asked questions about MMR vaccine safety and efficacy, concern over measles, and vaccine choice. This survey was fielded in April 2015. The vaccine safety question asked respondents' confidence in the safety of the MMR vaccine, and was coded on a four-point scale from "Not at all confident" to "Very confident", $12.1 \%$ of respondents answered that they were "Not at all confident" or "Not very confident" in the vaccine's safety.

To examine the effect of partisanship on vaccination, I used a question from the same survey which asked respondents if they would vaccinate their child for MMR, or if they would seek an exemption. ${ }^{4}$ Only $10.6 \%$ of respondents claimed that they would seek an exemption, a number which closely matched the percentage of respondents who expressed doubts about the safety of the vaccine.

\section{Measuring the Effect of Trust on Vaccination}

In this paper, I test the hypothesis that the partisanship of the president influences vaccination rates because it makes presidential out-partisans less likely to trust the government.

\footnotetext{
4 The measles data I use in this study derive from a pooled survey experiment. There was no difference across experimental conditions, and for the purposes of this paper, I collapse across the different experimental conditions. For additional information, please see the survey experiment section of the appendix.
} 
Fig. 1 Mediator Model. This model proposes one causal mediator-trust in government. The total effect is the sum of the direct effect of partisanship on perceptions of vaccine safety and the causal mediation effect of trust in government

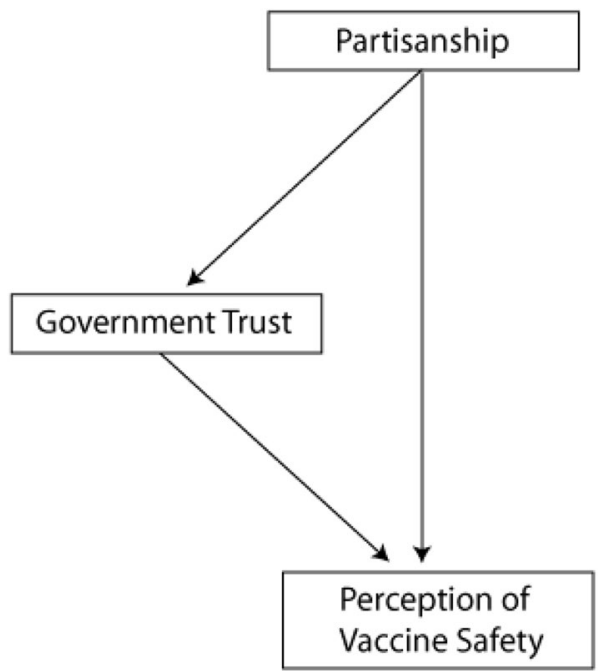

To test this, I use a causal mediator model which assesses the degree to which government trust explains partisan differences in beliefs about vaccine safety. Mediation analysis is used widely in the social sciences to test potential mechanisms through which a variable such as partisanship influences behavior. Mediator models make it possible to test whether a potential mediator completely or partially reduces the effect of partisanship on vaccine beliefs and behavior.

Some scholars have debated the effectiveness of mediation analysis, especially for observational data (Bullock et al. 2010). I present mediation analysis as only one piece of evidence for the partisan trust theory. If mediation analysis failed to find that trust in government was a significant mediator for partisanship in beliefs about vaccination, this would be a serious piece of evidence against my theory.

I ran a simple mediator model to test if government trust explained partisan differences in perceptions of vaccine safety, described in Fig. 1. According to my theory, partisan differences in government trust should explain differences in perceptions of vaccine safety.

Unfortunately, data about government trust were not available in the smallpox case, limiting my analysis to the H1N1 and measles cases. I use the mediation model presented in Imai et al. (2010) because it allows for the use of non-linear models such as ordered logit in the mediation analysis. ${ }^{5}$

In both the measles and H1N1 cases, I used partisans' self-reported perceptions of vaccine safety as my outcome variable. As the mediator variable, I used a variable that asked respondent about how often they trusted the federal government to

\footnotetext{
5 Additional information about the mediator model is available in the appendix.
} 
do the right thing. I limited my analysis only to Democrats/leaners and Republicans/ leaners in order to test the effect of being an out-partisan. ${ }^{6}$

\section{Behavioral Measures of Vaccination Rates}

While surveys have been found to be a reliable measure of vaccination behavior, I use actual vaccination data to determine whether survey differences in perceptions of vaccines translate into actual differences in behavior. To measure vaccination behavior, I examined kindergarten vaccination rates and personal belief exemptions in California from 2001 to 2015, spanning both the Obama and Bush administrations. Personal belief exemptions (PBEs) were a form of vaccine exemption in which parents could claim a religious or philosophical opposition to vaccination. ${ }^{7}$ PBEs provide a much clearer picture of anti-vaccine sentiment than overall vaccination rates, as parents may fail to vaccinate their children for any number of reasons such as the presence of a medically recognized condition that precludes vaccination or lack of access to healthcare.

If partisans are more likely to follow government recommendations when their party is in power, Republicans should be less likely to vaccinate after Obama took office. ${ }^{8}$ After 2008, there should be a drop in vaccination rates in districts with a higher proportion of Republicans. While the overall rate of vaccination in California may have decreased over time due to an overall increase in anti-vaccine sentiment, my theory predicts that it should be an uneven decrease, with more Republican districts posting greater numbers of exemptions post-2008.

To test this theory, I used a binomial logit regression with district-level random effects to estimate the effect of school district partisanship on the rate of vaccination and PBEs depending on the partisanship of the administration. Unlike a fixed effects model, a model with random effects allows me to estimate the effect of timeinvariant covariates (such as 2008 Democratic presidential vote percentage) on the outcome variable of interest while still accounting for the panel nature of the data. School district vaccination data is reported by providing the yearly number of students who are vaccinated, those who have PBEs, and the total number of students in the district. I use two different dependent variables of interest - overall vaccination rates, and personal belief exemption rates. My dependent variable in the PBE regression was the proportion of students who had personal belief exemptions. In the overall vaccination regression, the DV was the proportion of students who were vaccinated.

My main independent variable of interest, parental partisanship, was estimated by aggregating block-level election data from California's Statewide Redistricting

\footnotetext{
6 Pure Independents make up only about $10 \%$ of my sample, and running the mediation analysis using in-partisan (Dem) vs not in-partisan (Rep + pure Ind) yields basically the same results.

7 California banned PBEs in 2015.

8 While vaccination policy is decided at the state level, state level officials are much less visible than national level officials, and therefore the partisan composition of the state government is significantly less likely to influence partisans' level of government trust.
} 


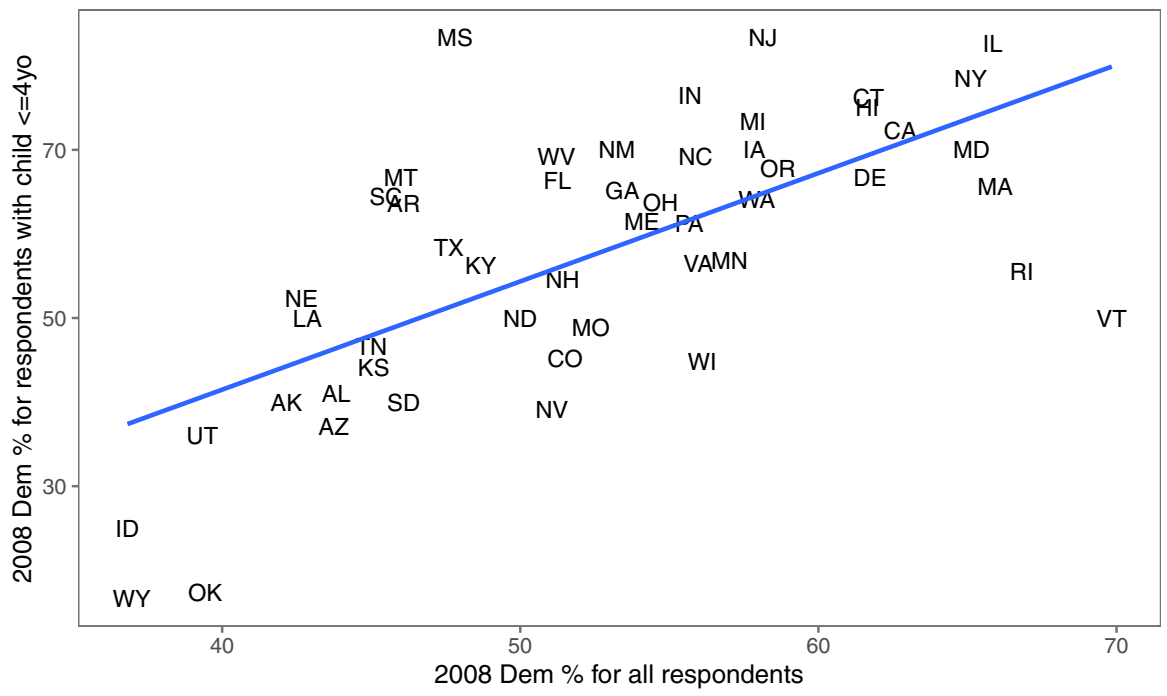

Fig. 2 State-level 2008 Democratic Vote among Parents and Non-Parents. There is a strong correlation between the 2008 presidential vote of parents with young children and the overall 2008 presidential vote in that state. Parents of young children are slightly more Democratic. The Y axis represents the state level $\%$ of CCES respondents with young children who reported voting Dem in the 2008 presidential election. The $\mathrm{X}$ axis represents the state level \% of all CCES respondents who reported voting Dem in the 2008 presidential election

database to determine the 2008 Democratic presidential vote percentage by school district. To ensure that block-level presidential vote accurately reflects partisanship of the parents within a school district, I used data from the 2012 CCES, which asked respondents both their 2008 vote choice and whether they had a child under the age of 5. Figure 2 shows the proportion of self-reported 2008 Dem vote by state among parents of a child under five versus all respondents. While respondents with young children are on average about $5 \%$ points more likely to vote Democrat than respondents without, the state-level correlation between under-5 parent vote and total population vote is about 0.7 . This suggests that presidential vote among the general population is a relatively accurate proxy for presidential vote among parents of kindergartners, as areas with more Democratic vote share will also have more Democrats among parents of young children.

The model to estimate the effect of partisanship on vaccination takes the form:

$$
Y_{i t}=\beta_{0}+\beta_{1} \text { DVote }_{i}+\beta_{2} \text { Obama }_{t}+\beta_{3} \text { DVote }_{i} * \text { Obama }_{t}+\beta_{4} \text { Year }_{t}+\beta x_{i}+u_{i}+\epsilon_{i t}
$$

In this model, $Y_{i t}$ stands in for the two outcome variables - (1) proportion of children in school district $i$ who have a personal belief exemption in year $t$ and (2) proportion of children in school district $i$ who are vaccinated in year $t$.

DVote $_{i}$ is the proportion of the two party 2008 votes that went to Barack Obama, the Democratic presidential candidate. Obama ${ }_{t}$ is a dummy variable that 
Republican President:
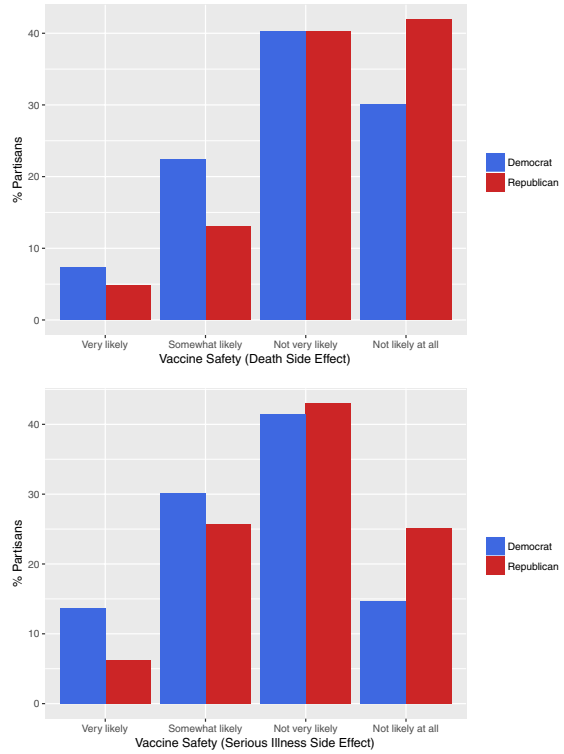

Democratic President:
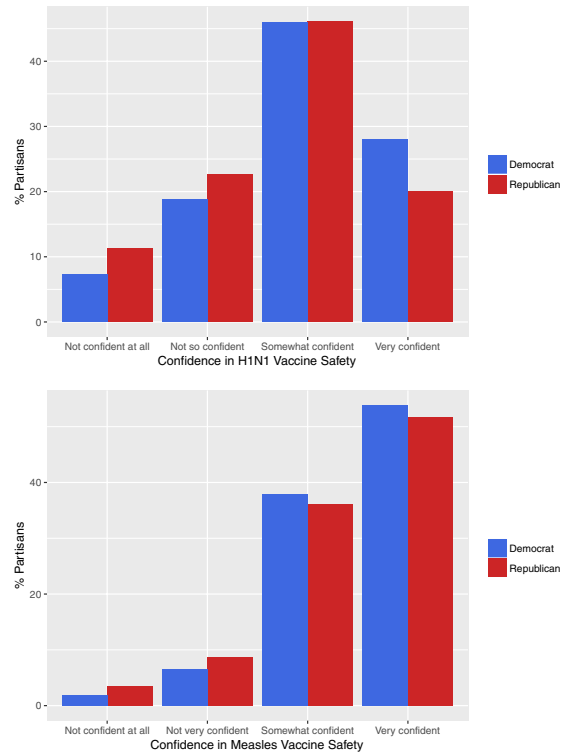

Fig. 3 Partisan Perceptions of Vaccine Safety. Presidential co-partisans are more likely to believe that vaccines are safe than presidential out-partisans. X-axis represents partisan perceptions of vaccine safety. For smallpox, X-axis is flipped (Partisans who say side effects are "Not Likely at All" are on the right, since they have the strongest belief in vaccine safety). Y-axis is percent of Democrats or Republicans who responded with each option

indicates whether year $t$ was during the Bush administration (2001-2008) or the Obama administration (2009-2015).

Thus, the main coefficient of interest is $\beta_{3}$, which measures the interaction between a district's partisanship and the Obama administration. The expectation is that $\beta_{3}$ is negative for personal belief exemptions (fewer PBEs in more Dem districts after Obama is elected) and positive for overall vaccination (more children vaccinated in more Dem districts). Year $r_{t}$ is the year $t$, and $\beta_{4}$ measures the linear time trend. $x_{i}$ is the vector of district-level demographic covariates (race, income, education, $\%$ urban) for each school district from the American Communities Survey. Finally, $u_{i}$ is the district-level random effect.

\section{Presidential Co-Partisans Are More Likely to Believe in Vaccine Safety}

Figure 3 plots the raw proportions showing partisans' perceptions of vaccine safety under a Republican and a Democratic president. As the figure shows, Republicans were more likely to believe that vaccines were safe under a Republican president (smallpox vaccine), and Democrats believed the opposite (H1N1, measles). Partisan survey responses to perceptions of vaccine safety seem to "flip" depending on the party of the president. 
Table 1 Partisan perceptions of vaccine safety

Republican President

Smallpox Safety

Smallpox Safety

(Illness side effect)

(Death side effect)

Pres. Co-Partisan (Rep)
Independent
Pres. Out-Partisan (Dem)
Full Table in Appendix...

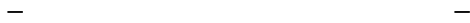

$-0.371^{*}(0.156)$

$-0.217(0.16)$

$-0.433^{* *}(0.163)$

$-0.33^{\dagger}(0.174)$

\begin{tabular}{lll}
\hline & Democratic President & \\
\cline { 2 - 3 } & H1N1 Safety & Measles Safety \\
\hline Pres. Co-Partisan (Dem) & - & - \\
Independent & $-0.212(0.263)$ & $-0.766^{* *}(0.077)$ \\
Pres. Out-Partisan (Rep) & $-0.624^{* *}(0.132)$ & $-0.378^{* *}(0.072)$ \\
Full Table in Appendix... & & \\
\hline
\end{tabular}

In all three cases (smallpox, H1N1, and measles), presidential co-partisans were significantly more likely to believe that vaccines were safe. All four columns represent the results of an ordered logit regression. For the smallpox questions, the order was flipped ("Not likely at all" was the largest value, "Not very likely" was second largest etc, as lower values of side effect concern represent higher confidence in vaccine safety). Full tables are in the appendix (regressions contain the following covariates: age, gender, race/ethnicity, income, education)

${ }^{\dagger} \mathrm{p}<0.1 ;{ }^{*} \mathrm{p}<0.05 ;{ }^{* *} \mathrm{p}<0.01$

Table 1 presents the ordered logistic regression estimates for perceptions of vaccine safety for the three vaccines. In all three cases, presidential co-partisans were significantly more likely to believe that the vaccine was safe. In the case of the smallpox vaccine, Republicans were more likely to believe that the vaccine was safe, while in the cases of H1N1 and measles, the opposite was true. This finding supports the hypothesis that partisans are more likely to believe that vaccines are safe when their party holds the presidency. In two of the three cases, Independents were also significantly less likely to believe that the vaccine was safe, a finding that cannot be attributed to partisan cues. Instead, it is likely that independents are less trusting of government than partisans irrespective of which party is in power..

The effect size of partisanship on perceptions of vaccine safety was substantial. On average, out-partisans (Democrats) were 11 percentage points more likely than co-partisans (Republicans) to believe that serious illness was a "very likely" or "somewhat likely" side effect of the smallpox vaccine, and 5 percentage points more likely to believe that death would be a "very likely" or "somewhat likely" side effect. In the case of the H1N1 vaccine, out-partisans (Republicans) were 10 percentage points more likely to say that they were "Not so confident" or "Not confident at all" in the safety of the H1N1 vaccine than co-partisans (Democrats). Finally, in the case of measles, out-partisans (Republicans) were 4 percentage points more likely than co-partisans (Democrats) to be "Not very" or "Not at all" confident in the safety of the measles vaccine. 
H1N1

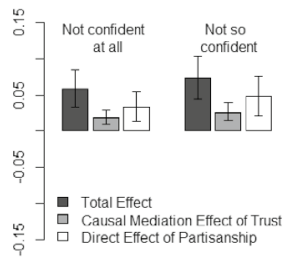

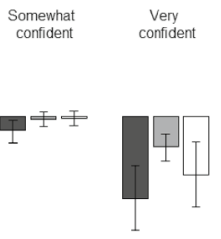

MMR

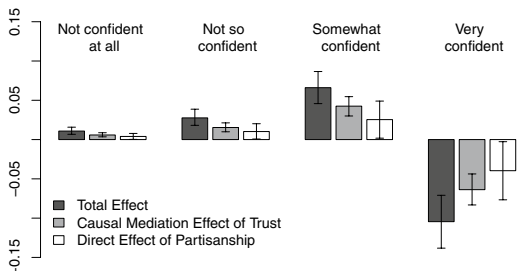

Fig. 4 Does government trust explain partisan differences in perceptions of vaccine safety? (Ordered Logits). Government trust is a significant mediator of the partisan vaccination gap in perceptions of vaccine safety. In the case of MMR, the direct effect of partisanship is no longer significant

This section has demonstrated that presidential co-partisans are indeed more confident in the safety of vaccines than presidential out-partisans. These effects are significant and sizable, ranging from $4 \%$ for the measles vaccine to $11 \%$ for the smallpox vaccine. The next section looks at the role of government trust as a mediator of partisan vaccination gaps.

\section{Government Trust Plays a Central Role in Safety Perceptions}

In order to examine the role of government trust in partisan perceptions of vaccine safety, I turned to causal mediation analysis. Unfortunately, there was no government trust question in the smallpox survey, so I could only do this analysis for the $\mathrm{H} 1 \mathrm{~N} 1$ and the measles vaccines.

I perform this analysis using several different model specifications for the mediator and the outcome variables. First, I use a model analogous to the ordered logistic regression presented in the previous section, where both the mediator and outcome variables are treated as ordered factors on a four point scale from "Not confident at all" to "Very confident", both in vaccine safety and their trust in the government's ability to do the rights thing. As in the models presented in the prior section, I control for age, gender, race, and education in both the outcome and mediator regressions.

Unfortunately, this specification precludes a sensitivity analysis (Tingley et al. 2013). In order to both verify my mediation results and perform a sensitivity analysis, I turn to a different specification, ${ }^{9}$ which treats both the mediator and outcome

\footnotetext{
${ }^{9}$ In the appendix, I also run two other models, one with a binomial probit as the mediator and a linear outcome, and the other with a linear mediator and binomial probit outcome, as well as the sensitivity analyses for these models. The binomial is coded as 0 for "Not at all" or "not very" confident, and 1 for "somewhat" or "very" confident. All three models (the only models for which sensitivity analysis is currently supported) provide very similar results in the size, significance, and sensitivity of the mediation effect.
} 
$\mathrm{H} 1 \mathrm{~N} 1$

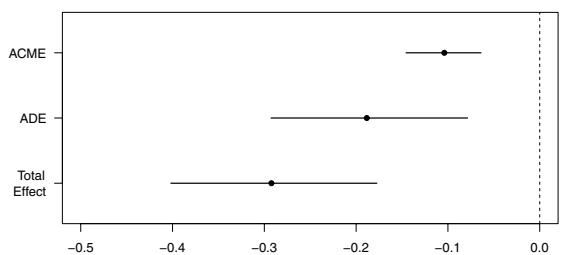

MMR

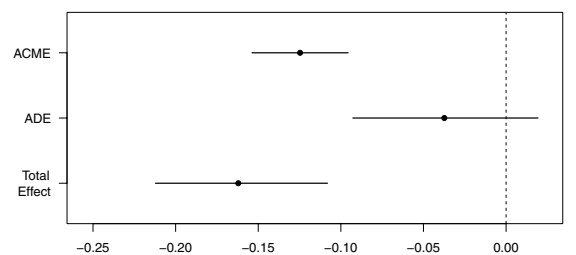

Fig. 5 Does government trust explain partisan differences in perceptions of vaccine safety? (OLS). The results for this model are very similar to those for the ordered logit. Once again, in the case of MMR the direct effect of partisanship is no longer significant

variables as linear variables rather than ordered factors, with "Not confident at all" coded as 1 and "Very confident" coded as 4.

Figure 4 plots the mediation effect of government trust on the partisan gap in vaccine safety perceptions using the ordered logit models. In both cases, government trust significantly mediates the effect of partisanship on perceptions of safety.In the case of H1N1, government trust mediates approximately $34 \%$ of the total partisan effect. In the case of measles, government trust mediates approximately $58 \%$ of the total partisan effect.

Figure 5 plots the same mediation effect using the linear models. As in the ordered logit models, government trust significantly mediates the partisan vaccination gap. Using this specification, government trust mediates approximately $34 \%$ of the total partisan effect on $\mathrm{H} 1 \mathrm{~N} 1$ vaccine safety, and $76 \%$ of the total partisan effect on MMR vaccine safety. A sensitivity analysis performed on these results using the methodology described by Imai et al. (2010) shows a $\rho$ of 0.3 for the H1N 1 vaccine and a $\rho$ of 0.15 for the measles vaccine, suggesting a modest degree of sensitivity to unobserved pre-treatment covariates. ${ }^{10}$

This section shows that government trust plays a powerful role in explaining partisan vaccination gaps. This provides additional support for my theory that partisanship shapes citizens' perceptions of their government's competence and trustworthiness, changing their willingness to comply with its recommendations. The next section looks at partisans' differential vaccination rates. ${ }^{11}$

\footnotetext{
${ }^{10}$ In order to further confirm these results, see the appendix for mediation and sensitivity analysis across several additional models.

${ }^{11}$ Perceptions of vaccine safety play a large role in partisans' willingness to vaccinate. Partisans' worries about the disease do not. For analysis of the relative contributions of vaccine safety and disease worry to partisans' vaccination decision, please see the appendix.
} 


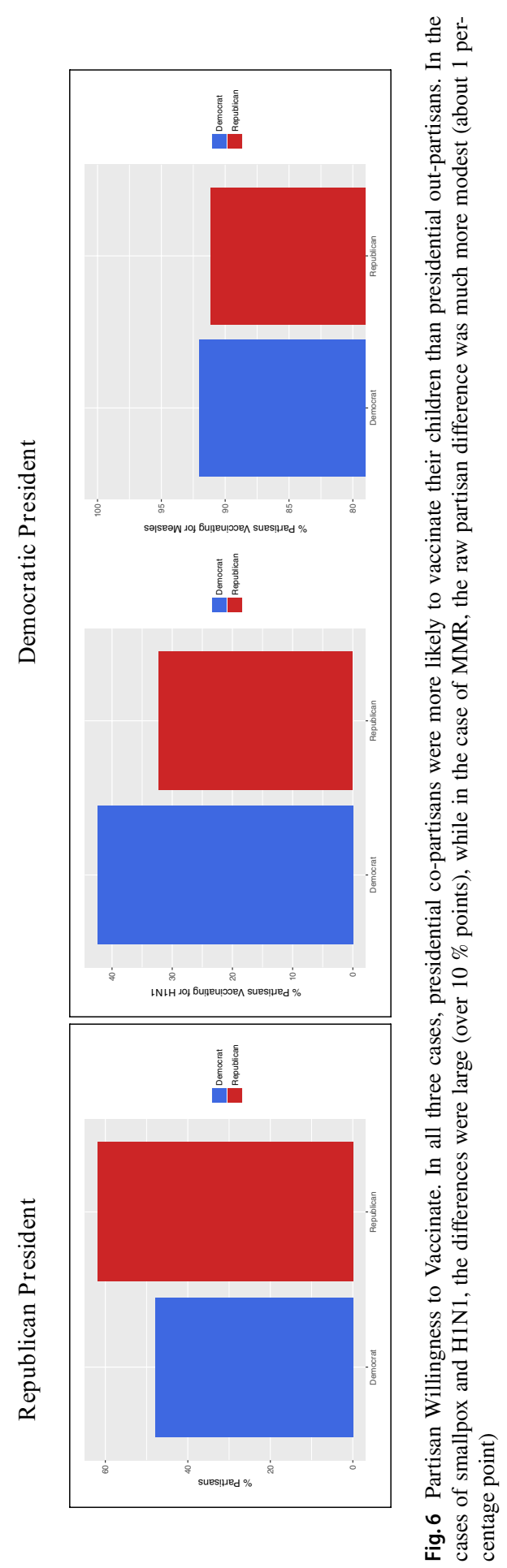


Table 2 Partisan Willingness to Vaccinate

Republican President

Smallpox

$\begin{array}{ll}\text { Pres. Co-Partisan (Rep) } & - \\ \text { Independent } & -0.572^{*}(0.253) \\ \text { Pres. Out-Partisan (Dem) } & -0.588^{* *}(0.146)\end{array}$

Full Table in Appendix...

Democratic President

$\mathrm{H} 1 \mathrm{~N} 1$

$\begin{array}{lll}\text { Pres. Co-Partisan (Dem) } & - & - \\ \text { Independent } & -0.403(0.286) & -1.012^{* *}(0.125) \\ \text { Pres. Out-Partisan (Rep) } & -0.449^{* *}(0.153) & -0.410^{* *}(0.134) \\ \text { Full Table in Appendix... } & & \end{array}$

In all three cases, presidential co-partisans were significantly more likely to vaccinate than presidential out-partisans. All three columns represent the results of a binomial logit regression. Full tables are in the appendix (regressions contain the following covariates: age, gender, race/ethnicity, income, education)

${ }^{\dagger} \mathrm{p}<0.1 ;{ }^{*} \mathrm{p}<0.05 ;{ }^{* *} \mathrm{p}<0.01$

\section{Co-Partisans Are More Likely to Vaccinate Their Children}

Figure 6 presents the raw percentage of partisans who would vaccinate themselves or their kids in the cases of smallpox, H1N1, and measles. In all three cases, presidential out-partisans (Dems for smallpox, Reps for H1N1 and measles) were less likely to report willingness to vaccinate than presidential co-partisans. Table 2 presents the binomial logit coefficient estimates on partisanship, confirming that the effect of partisanship on vaccination is statistically significant.

I calculated predicted effect size similarly to the previous section. In the cases of smallpox and $\mathrm{H} 1 \mathrm{~N} 1$, presidential co-partisans were about $10 \%$ points more likely to vaccinate than presidential out-partisans. For the measles vaccine, the effect size was closer to $3 \%$ points. The difference in effect size may be the result of a number of factors, including the familiarity of the MMR vaccine, its' administration to children, or the question wording. ${ }^{12}$

Now, while presidential co-partisans said they were more willing to vaccinate themselves and their children, was this an instance of cheap talk, or an indicator of genuine behavior? To test this question I relied on actual kindergarten vaccination and personal belief exemption data from the state of California over the course of the Bush and Obama administrations (2001-2015).

Figure 7 shows the raw change in PBE rates for each school district in California from the Bush to the Obama administrations. While the most Democratic school

\footnotetext{
12 The smallpox and H1N1 questions asked if respondent would or would not be willing to vaccinate. The measles questions asked if respondents would be willing to vaccinate or seek an exemption.
} 


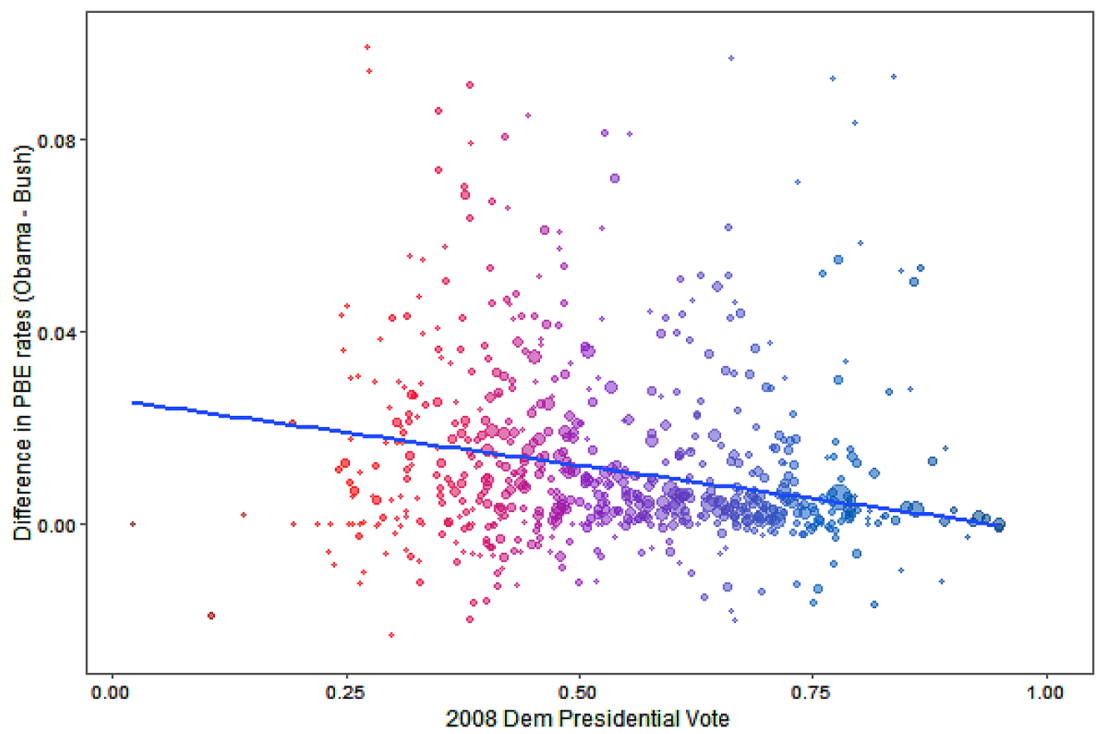

Fig. 7 Difference in PBE Rates by administration and partisanship. Partisanship significantly correlated with increases in personal belief exemptions after Obama became president. School districts with more Republican voters became much more likely to claim PBEs after Obama became president

Table 3 CA Vaccination and PBE Rates (2001-2015)

\begin{tabular}{lll}
\hline & \multicolumn{2}{l}{ Dependent variable } \\
\cline { 2 - 3 } & PBE Rate & Vaccination Rate \\
& $(1)$ & $(2)$ \\
\hline \% 2008 Dem vote & $0.889^{* *}(0.247)$ & $-1.714^{* *}(0.190)$ \\
Obama Admin & $0.454^{* *}(0.030)$ & $-0.657^{* *}(0.016)$ \\
\% 2008 Dem vote x Obama & $-0.347^{* *}(0.047)$ & $0.585^{* *}(0.022)$ \\
\hline
\end{tabular}

Presidential out-partisans became less likely to vaccinate after Obama was elected president. Both columns represent the coefficients of a binomial logit regression with random effects, with each child who received a PBE (1) or was vaccinated (2) as a 1 , and otherwise a 0 . Full tables are in the appendix (regressions contain the following school district level covariates: race/ethnicity, income, education)

${ }^{\dagger} \mathrm{p}<0.1 ;{ }^{*} \mathrm{p}<0.05 ;{ }^{* *} \mathrm{p}<0.01$

districts did not experience any increase in PBEs from the Bush to the Obama administration, the most Republican districts experienced an increase of about $3 \%$.

An effect of this magnitude represents a potentially serious public health problem, as it represents thousands of kindergartners missing out on vaccines. Some diseases, such as pertussis or measles, require $94 \%$ of a population to be vaccinated in order to achieve population immunity and prevent the spread of disease-a $3 \%$ 
Table 4 Controlling for Lag Vax-Preventable Disease

\begin{tabular}{lll}
\hline & \multicolumn{2}{l}{ Dependent variable: } \\
\cline { 2 - 3 } & PBE rate & Vaccination rate \\
\hline \% 2008 Dem vote & $0.762(0.762)$ & $-1.553^{*}(0.665)$ \\
Obama admin & $0.336^{* *}(0.041)$ & $-0.812^{* *}(0.024)$ \\
$\%$ 2008 Dem vote $\times$ Obama & $-0.443^{* *}(0.071)$ & $0.893^{* *}(0.047)$ \\
Lag VPD Rate & $-665.099^{* *}(36.115)$ & $-207.596^{* *}(17.859)$ \\
Lag VPD Rate x Obama & $347.527^{* *}(40.989)$ & $150.001^{* *}(30.091)$ \\
Full Table in Appendix & & \\
\hline
\end{tabular}

Including the rate of vaccine-preventable diseases in the regression did not change the effect of partisanship on vaccination rates. Full tables are in the appendix (regressions contain the following county-level covariates: race/ethnicity, income, education)

${ }^{\dagger} \mathrm{p}<0.1 ;{ }^{*} \mathrm{p}<0.05 ;{ }^{* *} \mathrm{p}<0.01$

increase in PBEs could easily put population immunity at risk. Table 3 confirms that after Obama's election, the increase in PBE rates was much larger in Republican school districts than in Democratic ones, as was the decline in vaccination rates. ${ }^{13}$

Using both survey and behavioral data, this section has demonstrated that presidential co-partisans are significantly more likely to vaccinate themselves and their children than presidential out-partisans. Next, I will test three alternative non-partisan hypotheses to highlight the stability of the partisan effect on vaccination.

\section{Alternative Explanations Do Not Account For Differences in Vaccination Rates}

In this section, I tackle threats to the validity of my behavioral results. First, laxity in vaccination has consequences. It is reasonable to expect that areas with fewer vaccinated children will have more disease outbreaks. This, in turn, should motivate school officials to more strictly enforce vaccination regulations. Perhaps the most Democratic school districts were on the front end of the anti-vaccine trend, then faced increasing rates of vaccine-preventable disease, which caused their vaccination rates to rise? If the increase in disease (and subsequent stricter enforcement of vaccine regulations) occurred around 2008, the outcome would be observationally equivalent to a partisan effect.

In order to test this alternative hypothesis, I relied on county-level disease data from the California Health and Human Services Department. ${ }^{14}$ To get the lagged vaccine preventable disease rate, I summed up the number of cases of Diphtheria, Tetanus, Pertussis, Measles, Mumps, Rubella, Hepatitis B, and Varicella Hospitalizations for the prior year, and then divided by the total county population. As the

\footnotetext{
${ }^{13}$ These results are highly robust to model specification, for more information please see appendix.

${ }^{14}$ https://data.chhs.ca.gov/dataset/infectious-disease-cases-by-county-year-and-sex.
} 
Table 5 Controlling for Lagged Vaccination Rate

\begin{tabular}{lll}
\hline & \multicolumn{2}{l}{ Dependent variable } \\
\cline { 2 - 3 } & PBE Rate & Vaccination Rate \\
\hline \% 2008 Dem vote & $0.429^{\dagger}(0.224)$ & $-1.058^{* *}(0.143)$ \\
Obama Admin & $0.460^{* *}(0.031)$ & $-0.339^{* *}(0.048)$ \\
\% 2008 Dem vote x Obama & $-0.230^{* *}(0.048)$ & $0.448^{* *}(0.023)$ \\
Lag PBE Rate & $3.171^{* *}(0.124)$ & \\
Lag PBE x Obama & $-1.756^{* *}(0.101)$ & \\
Lag Vaccination Rate & & $3.003^{* *}(0.047)$ \\
Lag Vaccination x Obama & & $-0.198^{* *}(0.048)$ \\
Full Table in Appendix & & \\
\hline
\end{tabular}

Including the lagged vaccination rate in the regression did not change the effect of partisanship on vaccination rates. Full tables are in the appendix (regressions contain the following school district level covariates: race/ethnicity, income, education)

${ }^{\dagger} \mathrm{p}<0.1 ;{ }^{*} \mathrm{p}<0.05 ;{ }^{* *} \mathrm{p}<0.01$

dependent variable, I aggregated the school district vaccination and PBE rates to the county level, and used county-level demographic covariates. Otherwise, the regression specification was identical to the specification in the prior section (Table 3 ). If partisan change in vaccination rates during the Obama administration is the effect of stricter vaccine enforcement in counties with high disease rates, including this variable in the regression should remove the significance on the Dem vote x Obama admin term.

Table 4 shows the results of the binomial logit regression. Including the lagged disease rate variable does not substantively change the results - Republicans still became less likely to vaccinate and more likely to claim PBEs during the Obama administration. This result is also robust to model specification. Removing the interaction between Obama admin and lagged disease does not change the results, nor does lagging the disease rate at 0,2 , or 3 years instead of 1 . Similarly, the Dem Vote $\mathrm{x}$ Obama Admin interaction is still significant if the lagged disease variable is completely removed. As such, it is unlikely that the partisan effect measured is the result of stricter vaccine enforcement in high-disease areas.

The second test concerns a potential "catch up" effect among under-vaccinated school districts. It is possible that given the rising concern around low vaccination rates, school district officials in districts with low rates began enforcing vaccination regulations more strictly even if they did not see an increase in disease outbreaks. ${ }^{15}$ To test this hypothesis, I added a lagged vaccination rate/ PBE rate covariate to the regression presented in Table 3, as well as an interaction between lagged vaccination $\times$ Obama admin (in case the "catch up" period

\footnotetext{
15 An alternative could also be true - anti-vaccine beliefs may have originally been popular in some school districts, which had lower vaccination rates, but eventually spread to other districts. This robustness check tests both possibilities.
} 
Table 6 Controlling for income effects

\begin{tabular}{lll}
\hline & \multicolumn{2}{l}{ Dependent variable } \\
\cline { 2 - 3 } & PBE rate & Vaccination rate \\
\hline \% 2008 Dem vote & $0.894^{* *}(0.247)$ & $-1.665^{* *}(0.190)$ \\
Obama admin & $0.460^{* *}(0.030)$ & $-0.609^{* *}(0.016)$ \\
$\%$ 2008 Dem vote x Obama & $-0.347^{* *}(0.047)$ & $0.509^{* *}(0.023)$ \\
Median HH Inc & $-0.090(0.057)$ & $0.176^{* *}(0.044)$ \\
Median HH Inc $\times$ Obama & $-0.020^{*}(0.008)$ & $-0.080^{* *}(0.004)$ \\
Full Table in Appendix & &
\end{tabular}

Including an interaction between school district level income and Obama admin did not change the effect of partisanship on vaccination rates. Full tables are in the appendix (regressions contain the following school district level covariates: race/ethnicity, income, education)

${ }^{\dagger} \mathrm{p}<0.1 ;{ }^{*} \mathrm{p}<0.05 ;{ }^{*} \mathrm{p}<0.01$

corresponded with the Obama administration). If the observed partisan effect is the result of under-vaccinated school districts "catching up", the interaction between Dem vote x Obama Admin should lose significance. Table 5 shows that for both vaccination rates and PBEs, including a lagged variable does not change the partisan effect. Changing the lag to 2 or 3 years does not change this result, nor does removing the interaction between Obama admin and the lagged variable. This means that it is unlikely that the partisan effect is the result of a "catch up" effect.

Finally, as my third robustness test, I look at the relationship between income and vaccination rates. It is possible that anti-vaccine sentiment may have first been popular among richer households, and then spread to poorer ones (or vice versa). If the time period in which anti-vaccine sentiment became popular among different economic strata corresponded to the Obama administration, then the partisan effect I observe may be the result of wealth, not partisanship. To test this effect, I added an interaction term between Obama admin x median household income to the equation from Table 3. If wealth is the true driver of the observed effect, the significance on the Obama x Dem vote coefficient should disappear.

Table 6 shows that the Obama administration effect for presidential co-partisans still holds even when I allow for the possibility of a wealth effect. This means that it is unlikely that the observed partisan effect is the result of income effects.

This final section has shown that the partisan effect in vaccination behavior is robust to disease, "catch up," and income effects, further demonstrating that the observed change in partisan vaccination rates was the result of a switch in the party of the presidency, as opposed to several other plausible mechanisms. 


\section{Conclusion}

Are presidential out-partisans less likely to comply with government recommendations? In the case of vaccination, the answer appears to be yes. Presidential out-partisans were significantly less likely to believe that vaccines were safe, and less likely to vaccinate their children than were presidential co-partisans. During the Bush administration, Democrats were both significantly more skeptical of the smallpox vaccine, and less likely to comply with mandatory school vaccination policies. During the Obama administration, the vaccination gap flipped and Republicans became more hostile to vaccines. These partisan differences in vaccine compliance were not the result of differential levels of worry about vaccine-preventable diseases, nor were they the result of stricter enforcement in under-vaccinated school districts. Instead, they could be largely attributed to partisan differences in perceptions of vaccine safety. Partisan differences in government trust significantly mediated partisan differences in perceptions of vaccine safety,

These findings carry important implications for public health campaigns in the era of polarization. First, messaging around government vaccination recommendations is important. A bipartisan message encouraging the uptake of vaccines in response to a public health crisis will be more effective for increasing vaccination than a message disseminated only by officials of the current presidential administration. For example, the MMR vaccine demonstrated smaller partisan gaps than did either the smallpox or the H1N1 vaccine, likely due in part to its' consistent recommendation by both Republican and Democratic presidential administrations. Second, presidential messages have the potential to hurt vaccination rates, and administrations should carefully weigh whether the president's increased visibility outweighs the potential backlash from members of the opposing party if the president announces a public health crisis or explicitly recommends a vaccine. Finally, this finding suggests that, to whatever degree possible, government agencies such as the FDA and the CDC should emphasize their independence from partisan politics. If Americans begin to view these agencies through an explicitly partisan lens, this could have serious repercussions for vaccination initiatives in the US.

In the 21st century, political partisanship has emerged as a key predictor not only of Americans' political behaviors, but of their non-political ones as well. Vaccination, while crucial to maintaining the nation's health, is only one form of government recommendation. If rising polarization causes partisans to selectively opt out of government health and safety recommendations when their party is out of power, this has dire public health consequences for the nation as a whole.

\section{References}

Baum, M. A. (2011). Red state, blue state, flu state: Media self-selection and partisan gaps in swine flu vaccinations. Journal of Health Politics, Policy and Law, 36(6), 1021-1059.

Braithwaite, J., \& Makkai, T. (1994). Trust and Compliance. Policing and Society: An International Journal, 4(1), 1-12. 
Brewer, N. T., Chapman, G. B., Gibbons, F. X., Gerrard, M., McCaul, K. D., \& Weinstein, N. D. (2007). Meta-analysis of the relationship between risk perception and health behavior: the example of vaccination. Health Psychology, 26(2), 136.

Bullock, J. G., Gerber, A. S., Hill, S. J., \& Huber, G. A. (2015). Partisan bias in factual beliefs about politics. Quarterly Journal of Political Science, 10, 519-578.

Bullock, J. G., Green, D. P., \& Ha, S. E. (2010). Yes, but what?s the mechanism?(don?t expect an easy answer). Journal of Personality and Social Psychology, 98(4), 550.

Canes-Wrone, B. (2010). Who leads whom?: presidents, policy, and the public. Chicago: University of Chicago Press.

Durbach, N. (2004). Bodily matters: The anti-vaccination movement in England, 1853-1907. Durham: Duke University Press.

Finucane, M. L., Slovic, P., Mertz, C. K., Flynn, J., \& Satterfield, T. A. (2000). Gender, race, and perceived risk: The'white male'effect. Health, Risk \& Society, 2(2), 159-172.

Gift, K., \& Gift, T. (2015). Does politics influence hiring? Evidence from a randomized experiment. Political Behavior, 37(3), 653-675.

Huber, G., \& Malhotra, N. (2012). Political sorting in social relationships: Evidence from an online dating community. In Annual Meeting of the American Political Science Association, New Orleans, LA. https://huber.research.yale.edu/materials/38_paper.pdf.

Imai, K., Keele, L., \& Tingley, D. (2010). A general approach to causal mediation analysis. Psychological Methods, 15(4), 309.

Iyengar, S., Konitzer, T., \& Tedin, K. (2017). The home as a political fortress; family agreement in an era of polarization. Technical report, Working Paper. https://pcl.stanford.edu/research/2017/iyengarhome-political-fortress.pdf.

Iyengar, S., Sood, G., \& Lelkes, Y. (2012). Affect, not ideology a social identity perspective on polarization. Public Opinion Quarterly, 76(3), 405-431.

Iyengar, S., \& Westwood, S. J. (2015). Fear and loathing across party lines: New evidence on group polarization. American Journal of Political Science, 59(3), 690-707.

Keele, L. (2005). The authorities really do matter: Party control and trust in government. Journal of Politics, 67(3), 873-886.

Lerman, A. E., Sadin, M. L., \& Trachtman, S. (2017). Policy uptake as political behavior: Evidence from the affordable care act. American Political Science Review, 111(4), 755-770.

Mac Donald, R., Baken, L., Nelson, A., \& Nichol, K. L. (1999). Validation of self-report of influenza and pneumococcal vaccination status in elderly outpatients. American Journal of Preventive Medicine, 16(3), 173-177.

Mason, L. (2016). A cross-cutting calm: How social sorting drives affective polarization. Public Opinion Quarterly, 80(S1), 351-377.

Nicholson, S. P., Coe, C. M., Emory, J., \& Song, A. V. (2016). The politics of beauty: The effects of partisan bias on physical attractiveness. Political Behavior, 38(4), 883-898.

Owen, A. L., \& Videras, J. (2008). Trust, cooperation, and implementation of sustainability programs: The case of local agenda 21. Ecological Economics, 68(1), 259-272.

Peterson, E., Goel, S., \& Iyengar, S. (2019). Partisan selective exposure in online news consumption: Evidence from the 2016 presidential campaign. Political Science Research and Methods,. https:// doi.org/10.1017/psrm.2019.55.

Pew Research Center (2010). Distrust, discontent, anger, and government rancor: The people and their government. http://www.people-press.org/files/legacy-pdf/606.pdf.

Pew Research Center. (2012). What the public knows about the political parties. Washington, D.C.: Pew Research Center.

PPew Research Center. (2016). Partisanship and political animosity in 2016. Washington D.C.: Pew Research Center.

Porter, D., \& Porter, R. (1988). The politics of prevention: anti-vaccinationism and public health in nineteenth-century england. Medical History, 32(3), 231.

Prior, M. (2013). Media and political polarization. Annual Review of Political Science, 16, 101-127.

Prior, M., Sood, G., Khanna, K., et al. (2015). You cannot be serious: The impact of accuracy incentives on partisan bias in reports of economic perceptions. Quarterly Journal of Political Science, 10(4), 489-518.

Schaffner, B. F., \& Clark, J. A. (2004). Macrotrust: Partisanship and the dynamics of trust in government. In annual meeting of the Southern Political Science Association, New Orleans, LA. January, 
pp. 8-11. http://citation.allacademic.com/meta/p_mla_apa_research_citation/0/6/7/9/8/pages67985/ p67985-1.php.

Sullivan, S. (2014, September). Just 36 percent of Americans can name which parties control house, senate. Washington Post.

The American National Election Studies (2017). The anes guide to public opinion and electoral behavior.

Tingley, D., Yamamoto, T., Hirose, K., \& Keele, I. K. (2013). mediation: R package for causal mediation analysis. $R$ Package Version, 4(3), 3-38.

Vegetti, F. (2014). From political conflict to partisan evaluations: How citizens assess party ideology and competence in polarized elections. Electoral Studies, 35, 230-241.

Zell, E. R., Ezzati-Rice, T. M., Battaglia, M. P., \& Wright, R. A. (2000). National immunization survey: the methodology of a vaccination surveillance system. Public Health Reports, 115(1), 65.

Publisher's Note Springer Nature remains neutral with regard to jurisdictional claims in published maps and institutional affiliations. 